\title{
LA NOCHE EN LA PRIMERA EDICIÓN DE LA REALIDAD Y EL DESEO DE LUIS CERNUDA
}

\section{Introducción}

El presente trabajo pretende ser una aproximación al universo simbólico de Luis Cernuda. Intentaremos recorrer la trayectoria vital del poeta durante los años de formación basándonos en el empleo del campo semántico de la noche tal como aparece en su obra.

Emplearé esencialmente la primera edición de $L a$ realidad y el deseo, la aparecida en 1936. ${ }^{1}$ Es en esta poesía donde encuentro un acento más apasionado, más auténtico y más directo. Como señala Octavio $\mathrm{Paz}^{2}$ el poeta en este periodo aún no es dueño de sí, pero precisamente esa impulsividad es la que le permite escribir sus mejores creaciones. Por otro lado, los seis libros que componen esta primera edición forman un ciclo completo y hasta cierto punto cerrado- que, al decir de varios críticos, es "el fruto más logrado, coherente y unitario de toda su obra". ${ }^{3}$ Por último, en esta primera edición es donde encuentro una mayor abundancia de valores simbólicos para la noche.

\section{La realidad y el deseo}

Situémonos en la obra que vamos a analizar. La edición de 1936 es un libro compuesto por seis colecciones de poemas, ordenados cronológicamente: Primeras poesías, Égloga, elegía, oda, Un río, un amor, Los placeres probibidos, Donde habite el olvido e Invocaciones a las gracias del mundo. ${ }^{4}$ Abarca la producción poética de Cernuda desde 1924 hasta 1936.

Octavio Paz distingue en esta primera obra dos partes: una primera "poesía de adolescencia", formada por Primeras poesías y Égloga, elegía, oda, y una segunda "poesía de juventud", compuesta por el resto de títulos. ${ }^{5}$ La división tripartita que propone Carlos P.

1 Sigo la edición de Miguel J. Flys: Luis Cernuda, La realidad y el deseo, Madrid, Castalia, 1982.

2 "La palabra edificante", en: «Papeles de son Armadans», XXXV/1964.

3 Miguel J. Flys, obra citada, Introducción, p. 36.

4 Primeras poesias recoge, ampliamente refundido, él primer libro poético de Cernuda, Perfil del aire, publicado originalmente en la revista (Litoral). El título de la última de las series reduce su nombre a Invocaciones en posteriores ediciones de La realidad y el deseo.

5 Octavio Paz, "La palabra edificante", artículo cit. Personalmente no comparto esta clasificación: ni creo adecuado denominar "de adolescencia" a una poesía compuesta cuando el autor se encuentra lejos de ese período vital, - -iene 23 ó 24 años-, ni me parece conveniente el tinte de imperfección que parece adquirir la poesía con esa etiqueta. En Perfil del aire se encuentran algunos poemas bellísimos y el poeta muestra ya algunos rasgos que le van a caracterizar en etapas posteriores. Por último, tampoco creo que haya que tildar de "poesía de juventud" al resto de los títulos: hay dos etapas claramente diferenciadas. 
Otero $^{6}$ me parece más acertada. El libro se dividiría en una fase inicial, otra surrealista y una tercera de corte romántico, cada una de las cuales estaría compuesta por dos títulos.

Primeras poesías presenta un ambiente crepuscular o nocturno y, en él, una estancia -ocasionalmente un jardín - esquemáticamente decorada, donde el poeta se encuentra, imbuido en una melancolía indolente. Formalmente emplea el metro corto -heptasílabo casi siempre-; los poemas son breves y la palabra es exacta y concisa. ${ }^{7}$ En el libro aparece el espíritu solitario de Cernuda: no aparece ningún otro ser humano. Los objetos están contemplados desde una perspectiva de lejanía, de distanciamiento del observador. Este distanciamiento es mucho mayor en las décimas que en los poemas que se intercalan entre los poemas más extensos, hasta tal punto que algunas décimas parecen meros ejercicios de estilo.

En el libro se encuentra ya la conciencia de un mundo interior y otro exterior. Ese mundo externo al poeta, e inaprehensible, se separa del interno por medio de elementos que son genéricamente denominados simplemente muro. El punto de contacto entre ambos mundos lo constituye una ventana a través de la que el poeta divisa objetos estáticos. En el interior de la estancia, el poeta se nos presenta en una actitud indolente y como desorientado. Ambos estados anímicos se explican por el conflicto que le plantea al poeta la conciencia de que existe en él una fuerza oculta, un afán íntimo, pero se ve incapaz de expresarlo. Junto a esta presentación, más bien velada, de su deseo, aparecen las referencias a la incapacidad para expresarlo, para darle forma mediante la palabra. El contraste entre la realidad y el deseo no es en este libro aún un enfrentamiento hostil, precisamente por esa vaguedad e indefinición. Tanto una como otro aparecen envueltos en sombra, de ahí que la presencia de la noche sea una constante en la mayoría de los poemas.

En "Historial de un libro" nos da Cernuda la clave para entender el segundo libro, Égloga, elegía, oda. Esta colección consta de los tres poemas indicados en el título más un "Homenaje" dedicado a Fray Luis de León. Cuenta Cernuda que el libro surgió como reacción a las críticas recibidas por Perfil del aire. Acusado de esa supuesta imitación de Guillén y de ausencia de novedad, opta por cultivar precisamente eso que se le critica. Surgen, de este modo, las composiciones señaladas, de corte clasicista, garcilasiano. Reconoce el autor que se trata de "ejercicios sobre formas poéticas clásicas... sin duda provechosas para mi adiestramiento técnico"8, pero al mismo tiempo encuentra que no le satisfacen, ya que no hay en ellas impulso vital:

Unas palabras de Paul Eluard, "y sin embargo nunca he encontrado lo que escribo en lo que amo", pero al revés, "y sin embargo nunca he encontra-

6 “Cernuda, poeta de Europa" en: «Papeles de son Armadans》, XXIX/1963, pp. 127-137.

7 Esta coincidencia formal con la obra de Guillén, Cántico, hizo que la crítica, — salvo excepciones como Bergamín y algunos catalanes- recibiera fríamente Perfil del aire, por considerar que era una imitación. Tal recibimiento dolió mucho a Cernuda, que en numerosas ocasiones a lo largo de su vida hace referencia a este episodio.

8 Luis Cernuda, "Historial de un libro" en: Poesía y Literatura, Iy II, Barcelona, Seix-Barral, 1971, p. 184. 
do lo que amo en lo que escribo" cifraba mi decepción frente a aquellas tres composiciones. ${ }^{9}$

A pesar de todo esto, Égloga, elegía, oda es un libro importante para entender a Cernuda, no sólo como poeta, sino también como ser humano. La colección nos muestra un autor que domina perfectamente los resortes técnicos de la poesía y que es capaz de componer poemas más extensos sin que se resienta el hálito poético. Esta será una característica presente en su producción posterior.

Los aspectos biográficos que se adivinan tras estas composiciones no se reducen a un enfrentamiento con la sociedad, -otra de las constantes cernudianas-. La dialéctica entre la realidad y el deseo aparece en "Elegía", donde además de mantenerse el ambiente nocturno y la estancia semidesnuda de los poemas de la serie anterior, el poeta presenta el contraste entre el deseo que le produce un contorno juvenil desnudo vagamente entrevisto en la penumbra y la realidad que le muestra que todo ha sido producto de su fantasía. Es la primera vez que aparece la figura humana, el otro, aunque se trate de una sombra. También en "Oda" aparece la descripción de un cuerpo masculino, el del joven dios protagonista del poema. En definitiva, Égloga, elegía, oda contiene, en germen, los elementos temáticos de la obra poética de Cernuda.

A partir de Un rio, un amor la voz de Cernuda adquiere una modulación totalmente diferente. La serie anterior era un callejón sin salida, de modo que hay que optar por la ruptura. Dos hechos importantes ayudan en este hecho: un viaje a Madrid y París y el descubrimiento del surrealismo. El viaje supone una liberación del ambiente provinciano en que vivía; el surrealismo le permitirá expresar su peculiaridad personal. ${ }^{10}$ Predominan en esta serie los versos largos y desaparece la rima, quedando el poeta dotado de una libertad plena para expresar su mundo subconsciente. El elemento nocturno sigue teniendo un papel importantísimo, pero ahora adquiere esa nueva dimensión que le otorga el surrealismo: el mundo exterior está visto en función de las vivencias internas. La realidad, vista desde el prisma de los deseos del poeta, se torna oscura, sombría, ruinosa, porque el estado anímico del autor se encuentra en una situación desesperanzada, sin luz. No obstante, cuando se refiere a espacios lejanos al poeta, soñados, la realidad es alegre, activa, luminosa, juvenil.

El siguiente libro, Los placeres prohibidos supone un paso más, el definitivo, en el proceso liberalizador de la palabra cernudiana. El verbo se hace más directo, más sensual. El libro saca a la luz pública la realidad de los sentimientos amorosos del poeta, su homosexualidad; aspecto esencial para entender la obra del autor. ${ }^{11}$ Formalmente, en esta serie,

9 "Historial...", articulo citado, p. 184.

${ }^{10}$ Como señala Octavio Paz, "fue el primero y casi el único que comprendió e hizo suya la verdadera significación del surrealismo como movimiento de liberación, - no del verso, sino de la conciencia -". ("La palabra edificante", artículo citado).

11 "Se corre el riesgo de no comprender el significado de su obra si se omite o se atenúa su homosexualidad, no porque su poesía pueda reducirse a esa pasión, -eso sería tan falso como ignorárlo-, sino porque ella es el punto de partida de su creación poética." (Octavio Paz, "La palabra edificante", artículo citado). 
se emplean técnicas surrealistas, desapareciendo por completo las estrofas, la regularidad de los versos, etc.: el poema se ajusta exclusivamente a la necesidad expresiva del autor, sin otra sujeción.

Donde habite el olvido, título tomado de un verso de la "Rima LXVI" de Bécquer, surgió como una sórdida historia de amor ${ }^{12}$ y supone un abandono casi definitivo del surrealismo. Vuelven de nuevo las composiciones breves y el metro corto. El objetivo del poeta pasa a ser "olvidar un olvido", o sea "lograr un estado de inconsciencia total que borre cualquier recuerdo del pasado".13 La noche va a adoptar el significado de "olvido" y, en un paso más, el de "muerte". Lo que en Los placeres prohibidos sólo estaba insinuado, se torna ahora identidad: el binomio noche/muerte se convierte en un par de sinónimos que representan el estado anímico del poeta.

Cierra esta primera edición de La realidad y el deseo la serie titulada Invocaciones a las gracias del mundo, diez poemas en los que se hace una especie de recapitulación de la vida del autor hasta el momento. El poeta parece detenerse a reflexionar, estableciendo sus relaciones con las distintas "gracias del mundo": el amor, la soledad, la tristeza, la poesía, el deseo, el viento, el mar y la noche.

\section{La noche de Cernuda}

Una de las funciones primordiales del poeta, del verdadero poeta es la de redescubrir los vocablos, la de encontrar significaciones nuevas que otorguen a las palabras dimensiones no exploradas aún. Si lo esencial del lenguaje poético es el extrañamiento, según es sabido, éste se puede conseguir de dos formas: empleando elementos de uso no cotidiano o bien, dotando de significaciones nuevas, mediante asociaciones de sentidos poco habituales, a los términos de uso común. Mediante este segundo procedimiento las palabras se recargan de contenido semántico y aparece, como señala Manuel Alvar, "una tercera dimensión, más allá del significante y del significado, la intencionalidad que le da el creador". ${ }^{14}$ Esto es lo que hará Cernuda con el campo semántico de la noche.

Debemos hacer una precisión: Cernuda no añade ninguna significación absolutamente nueva al término. Como veremos, todas las connotaciones que va adquiriendo el vocablo han aparecido ya antes, desde la mitologia y a través de la historia. Pero hecha esta precisión, hay que añadir inmediatamente otra: la noche de Cernuda adquiere una dimensión única en el sentido en que se trata de $s u$ noche, de la noche particularísima del poeta, de un elemento imprescindible en la evolución y en la comprensión de su "verdad verdadera". El extrañamiento que consigue el poeta no se logra, pues, con una connotación de

12 Asi nos lo describe el autor en Ocnos (Barcelona, Seix-Barral, 1989): "Subias a la casa, entrabas en el salón ... deseando tanto la presencia como la ausencia de un ser, pretexto profundo de tu existencia de entonces. [...] Y sonreías, conversabas, aunque, dentro de poco, tuvieras que encerrarte en una habitación, tendido contigo a solas en un lecho, revolviendo por la memoria los episodios de aquel amor sórdido y lamentable, sin calma para reposar la noche, sin fuerza para afrontar el dia" (pp. 106-107).

13 Derek Harris, obra citada, pp. 106-107.

${ }^{14}$ Manuel Alvar, “La Noche oscura en Dámaso Alonso", en: «Cuadernos Hispano Americanos» 280-282/1973, pp. 112-175. 
valor universal sino, precisamente, a través de la tremenda carga individual e intimista. La noche de Cernuda deviene, de este modo, un término extrañado.

Análisis cuantitativo del léxico relacionado con la noche ${ }^{15}$

\begin{tabular}{|l|r|r|r|r|r|r|l|}
\hline & $P P$ & $E G L$ & $R f O$ & $P L A$ & $D O N$ & $I N V$ & \\
\hline \hline Noche/nocturno & 11 & 3 & 30 & 6 & 4 & 9 & $=63$ \\
Luz escasa/luz fugitiva & 11 & 4 & 2 & - & 1 & 1 & $=19$ \\
Crepúsculo/Tarde/Ocaso & 3 & 2 & 1 & 2 & 2 & 2 & $=12$ \\
Alba/Amanecer/Aurora & 4 & 2 & 2 & - & 1 & 2 & $=11$ \\
\hline Sueño/soñar & 13 & 5 & 7 & 7 & 6 & 8 & $=46$ \\
Lámpara/Llama & 6 & 2 & 3 & - & 2 & - & $=13$ \\
Luna & 1 & - & 2 & 4 & 2 & 3 & $=12$ \\
Estrellas & 3 & - & 9 & 4 & - & - & $=16$ \\
\hline Sombra/sombrío & 7 & 10 & 19 & 8 & 9 & 12 & $=65$ \\
Nube & 1 & 1 & 11 & 5 & 4 & 4 & $=26$ \\
Niebla & 1 & - & 8 & 2 & 1 & 2 & $=14$ \\
Bruma/Humo/Penumbra & 2 & 3 & 1 & - & 1 & - & $=7$ \\
Borroso & - & - & - & - & 1 & - & $=1$ \\
Negro & 3 & - & - & - & 1 & 10 & $=14$ \\
Oscuridad/Oscuro & 1 & 5 & 3 & 4 & 2 & 3 & $=18$ \\
Tiniebla & - & 1 & - & 1 & - & 1 & $=3$ \\
Secreto & 3 & 2 & 3 & - & - & 1 & $=9$ \\
Olvido/Olvidar & 3 & - & 7 & 2 & 9 & 3 & $=24$ \\
Ceniza/Ceniciento & - & 1 & 3 & 3 & 1 & - & $=8$ \\
Polvoriento & - & - & - & - & - & 1 & $=1$ \\
Gris & - & - & 6 & - & - & 3 & $=9$ \\
Dormir & 4 & 1 & 10 & 4 & - & 1 & $=20$ \\
Sepultado & - & - & - & - & 4 & - & $=4$ \\
Muerte/Morir & - & - & 15 & 6 & 20 & 20 & $=61$ \\
\hline
\end{tabular}

He recogido en la tabla anterior los términos que se relacionan con el campo semántico de la noche en el libro de Cernuda. El primer apartado corresponde a los vocablos más esencialmente denotativos, aunque la adición de sintagmas y adjetivos van cargando connotativamente a los sustantivos. El segundo y el tercer grupo de elementos son los referentes empleados principalmente para dotar a noche de su carga positiva o negativa respectivamente.

15 Las siglas que encabezan la tabla se corresponden con cada uno de los títulos que componen La realidad y el deseo. 
Una primera aproximación nos muestra que los términos más repetidos son sombra, noche y muerte, por este orden. Pero hay que anotar que el referente muerte no aparece en la poesía de Cernuda hasta Un río, un amor.

Se puede observar así mismo, cómo los términos más específicamente denotativos son predominantes en la primera parte de La realidad y el deseo y que, a medida que avanza la producción, la obra se va cargando negativamente en cuanto a términos y significados, afectando en particular a los que conllevan una mayor carga emocional. Los sintagmas referidos a la noche como "momento del día", los referidos a "sombra" y los referidos a "muerte" presentan esta distribución respecto a la división tripartita del libro:

\begin{tabular}{|l||c|c|c|}
\hline & I Parte & II Parte & III Parte \\
\hline \hline Noche & 14 & 36 & 13 \\
\hline Sombra & 18 & 25 & 21 \\
\hline Muerte & 0 & 21 & 40 \\
\hline
\end{tabular}

Como se observa de un modo evidente, en la obra se produce una tendencia progresiva hacia los sintagmas de significación nihilista desde las primeras composiciones hasta las últimas.

Es importante destacar también la notoria presencia de valor positivo. Sin entrar aún en su consideración más detallada, de la que me ocuparé más adelante, hay que anotar el semiequilibrio que se establece entre términos lumínicos (generalmente de valor positivo) y términos oscuros (de significación negativa). Por supuesto, la presencia de estos últimos es más numerosa en el recuento que he efectuado, ya que me he centrado particularmente en los que tienen una relación más directa con noche. He dejado fuera otros vocablos como sol, luz, etc., por escapar un tanto del objeto de estudio que pretendo. Pero, aún así, términos como lámpara, llama, luna, estrellas, o el destacado soñar/sueños hacen de contrapeso a ese mundo oscuro, mortuorio, que puebla las páginas de la obra. $\mathrm{Y}$ esto es así porque la obra se presenta como un enfrentamiento entre dos polos: desde el propio título, la realidad se opone al deseo, la sociedad se opone al individuo, el otro se opone al yo. En este mundo de antítesis, la luminosidad se enfrenta a la oscuridad como elementos en constante lucha, en trasiego sin término.

Un último aspecto es el equilibrado reparto que presentan los términos referidos a atardecer frente a amanecer. Como se ve en la tabla I, el primero aparece en 12 ocasiones y el segundo en 11. Ese reparto equitativo parece indicar que no tienen el valor temporal perfectamente determinado sino que los emplea Cernuda con el valor genérico de "espacio de tiempo opuesto al día", es decir, como variante de noche.

\section{La noche: denotación}

El primer acercamiento a la noche en la poesía de Cernuda debemos hacerlo a partir de su significación denotativa. La voz noche está definida en el Diccionario de la Real Academia como "tiempo en que falta sobre el horizonte la claridad del sol". He aquí el 
punto de partida. La noche es un periodo temporal, un momento concreto en el decurso del tiempo. Este elemento es importante, y ya se ha puesto de relieve la importancia de la dimensión temporal en la poética cernudiana. ${ }^{16}$ En esta importancia del tiempo, la noche tiene un papel preponderante, la noche real, el momento del día en el que no hay luz del sol.

La noche a la ventana.

$$
(P P, \mathrm{XVI}, 1)
$$

$\mathrm{Y}$ el aire fresco vuelve

Con la noche cercana.

$$
(P P, \text { XXIII, 17-18) }
$$

En tanto el poeta en la noche otoñal

Bajo el blanco embeleso lunático

Mira las ramas...

$$
\text { (INV, “A las estatuas de los dioses", 41-43) }
$$

Esta inequívoca referencia a la temporalidad concreta raramente se presenta sin adjetivación, que suele ser de carácter subjetivo en la mayoría de los casos. Será, a través de ella, de la adjetivación, de la manera en que el término vaya dotándose de connotación. La noche, sin perder en ningún momento este primigenio carácter denotativo, va a pasar a ser símbolo de otras cosas, va a significar diferentes estados anímicos, va a representar anhelos, sueños, esperanzas, caídas del autor en su trayectoria vital. Pero siempre a partir de este significado original.

\section{La noche: connotaciones}

Puede ser interesante, para aproximarnos al valor simbólico de la noche, citar el epígrafe que a este voz dedica Juan Eduardo Cirlot en su Diccionario de símbolos ${ }^{17}$ :

Noche: relacionada con el principio pasivo, lo femenino y el inconsciente. Hesíodo le dio el nombre de madre de los dioses por ser opinión de los griegos que la noche y las tinieblas han precedido a la formación de todas las cosas. Por ello, como las aguas, tiene un significado de fertilidad, virtualidad, simiente. Como estado previo no es aún el día, pero lo promete y prepara. Tiene el mismo sentido que el color negro y la muerte en la doctrina tradicional.

Puede esta definición servir de guía para acercarnos al valor que la noche presenta en Cernuda. Me interesa destacar ahora algunos términos: principio pasivo, inconsciente, vir-

\footnotetext{
16 Ricardo Molina, "La conciencia trágica del tiempo. Clave esencial en la poesia de Luis Cernuda" en: Derek Harris, obra citada, pp.102-110.

$174^{\mathrm{a}}$ edición, Barcelona, Labor, 1981.
} 
tualidad, promesa y preparación, negro, muerte. ${ }^{18}$ Prácticamente será este mismo camino señalado por Cirlot el que recorra el poeta en la obra.

Podemos entrever desde un primer momento dos valores diferentes: unos de carácter positivo representado por los términos virtualidad, promesa y preparación, y otros de índole negativa, principio pasivo, negro, muerte. A estos valores hay que añadir dos dimensiones más que aparecen unidas a lo antes expuesto, la de la tristeza y la del miedo.

\section{a) La noche como virtualidad, promesa y preparación}

Un primer aspecto de la noche es que se trata del momento del día en el que el poeta se entrega a sus fantasías, a sus sueños. Lo encontramos en "Cuerpo en pena", donde el poeta, trasmutado en ahogado, recuerda momentos de placer que sucedieron una noche y que quizá regresen un día:

Flores de luz tranquila despiertan a lo lejos,

Flores de luz quizá o miradas tan bellas

Como pudo el ahogado soñarlas una noche

$$
\text { (RÍO, 17-19) }
$$

Por otro lado, la noche es el momento idóneo para entregarse a placeres y contemplaciones de tipo narcisista. Es un aspecto que tiene más importancia en la primera parte de su obra y que, poco a poco, se irá revelando menos satisfactorio. Si en un primer momento

Se goza en sueño encantado

Tras espacio infranqueable

Su belleza irreparable

El Narciso enamorado

$$
(P P, \text { XIII, 1-4) }
$$

posteriormente, la soledad se torna insoportable y se siente la necesidad del otro.

Mientras aguardo que tu propia presencia

Haga inútil este triste trabajo

De ser yo solo el amor y su imagen.

$$
\text { (PLA, "Veía sentado", 20-22) }
$$

En "A un muchacho andaluz", la noche, como lugar de encuentro con el amado, adquiere esa doble dimensión entre lo agradable y lo desagradable, entre el placer y el dolor:

Y tus labios, de fulmíneo bisel,

Eran la vida misma,

Como una ardiente flor

18 También es importante la relación que establece Cirlot entre la noche y el agua, por la importancia que este líquido adquiere en la obra de Cernuda. En ocasiones presentan significaciones muy próximas. Este aspecto ha sido estudiado por A. E. Virkel, "El simbolismo de las aguas en la poesía de Cermuda", en: "Cuadernos del Sun), X/1969, Bahía Blanca. 
Nutrida con la savia

De aquella piel oscura

Que infiltraba nocturno escalofrío

(INV, 15-20)

La premonición de logros amorosos, presente en numerosos poemas, se convierte en una realidad paulatinamente. En una primera etapa la noche se convierte en el espacio temporal en el que habitan seres que, como el autor, buscan amores imposibles. En el poema "Linterna roja" aparecen unos seres oscuros, mendigos, reyes sin corona perdidos en la noche,

Que buscaron la dicha más allá de la vida,

Que buscaron la flor jamás abierta,

Que buscaron deseos terminados en nubes

$$
\text { (RÍO, 10-12) }
$$

La noche es, sobre todo, promesa del amor, ese amor que la sociedad impide que se muestre a pleno sol. La noche y las sombras serán los elementos en los que ese amor prohibido se desarrolle. Deja entonces de ser la noche el espacio de lo posible y pasa a ser el tiempo del encuentro real:

Quedamos diluidos en la sombra

Anónimo destino que rozan gritos hostiles

En noches de placer.

(PLA, "Quisiera saber por qué esta suerte", 24-26)

Otro aspecto positivo es el que presenta la noche cuando se trata de espacios lejanos. En ellos es fácil realizar los sueños, la utopía personal. Los lugares hacen referencia principalmente a escenarios de Estados Unidos, donde la vida le parece más cercana "al ideal juvenil, sonriente y atlético". ${ }^{19}$ Allí las noches son tiempos cargados de promesas y realizaciones. De hecho, no hay separación entre la noche y el día, entre la sombra y la luz, puesto que ambas son hermosas:

En el sur tan distante quiero estar confundido (...)

Su oscuridad, su luz son bellezas iguales.

$$
\text { (RÍO, "Quisiera estar solo en el Sur", } 9 \text { y 12) }
$$

En Nevada,

Las noches transparentes

Abren luces soñadas

Sobre las aguas o tejados puros

Constelados de fiesta.

$$
\text { (RÍO, "Nevada", 5-8) }
$$

La realidad inmediata en la que vive el poeta es triste, oscura e impide que el hombre pueda manifestarse como es o, lo que es lo mismo, desarrollarse plenamente. La sociedad

19 “Historial...", art. cit., p. 189. 
ha ido creando un sistema de relaciones en el que el amor acaba ahogándose, tanto el amor homosexual como el heterosexual. La salida es huir en el espacio o en el tiempo, lograr la utopía mediante el sueño. 20

Dentro de las significaciones positivas de la noche en Cernuda aparece a menudo como el tiempo en que el poeta goza del amor. Ese amor se transforma en sentimiento panteísta que alcanza a todo el universo. El amor físico se universaliza y se extiende a todo porque no está ya ligado a nadie en concreto sino que pretende ser un amor que alcance a la totalidad. Este valor lo adquiere principalmente en la última de las colecciones de poemas.

Pero tú y yo sabemos (...)

Que cuando el hombre no tiene ligados sus miembros por las encantadoras mallas del

[amor

Cuando el deseo es como una cálida azucena

Que se ofrece a todo cuerpo hermoso que fluja a nuestro lado

Cuánto vale una noche como ésta, indecisa entre la primavera última y el estío primero

Ese instante en que oigo los leves chasquidos del bosque nocturno

Conforme conmigo mismo y con la indiferencia de los otros,

Solo yo con mi vida,

Con mi parte del mundo.

$$
\text { (INV, "Dans ma péniche", 48-57) }
$$

El valor simbólico de la noche como promesa queda subrayado por el empleo de elementos luminosos: luna, lámpara, estrellas, llama. Ya vimos cómo estos términos mantienen una presencia constante y destacada en la poética cernudiana. $\mathrm{Y}$ apuntamos que, en el empleo de estos elementos se percibe una evolución hacia un simbolismo cada vez mayor.

En las primeras poesías suelen tener como referente elementos reales: las estrellas y la luna son los cuerpos celestes nocturnos, la lámpara y la llama son los objetos tangibles que producen calor y luz:

En su paz la ventana

Restituye a diario

Las estrellas.

$$
(P P, 1,17-19)
$$

${ }^{20}$ En relación con esto hay que señalar el interés de Cernuda por el cine, la fascinación que le produjo desde el primer momento. Posiblemente ve en él un modo perfecto de escapar de la realidad opresiva y es el espacio en el que pueden realizarse los anhelos. Fue el cine, con su juego de luces y sombras, con sus proyecciones en semioscuridad, el inspirador de muchos de los poemas de Un rio, un amor. Véase "Historial de un libro", art. cit., pp. 187-188. Las referencias son constantes en su correspondencia: películas que ha visto, que quiere ver, atuendo de los actores, etc, (en: «Insula», 207/1964, Madrid). En este mismo sentido hay que señalar la fascinación por el jazz, que tiene para Cernuda las mismas características de ensoñación que el cine. ("Historial...", pp.187-189). 
El tiempo en las estrellas

$$
(P P, \mathrm{II}, 17)
$$

Es la atmósfera ceñida;

Sólo centellea un astro

Vertiendo luz de alabastro

Con pantalla adormecida

$$
(P P, \mathrm{XI}, 1-4)
$$

Surge viva la lámpara

En la noche desierta

$$
(P P, \mathrm{XXI}, 5-6)
$$

La llama tuerce su hastío,

Sola su viva presencia,

Y la lámpara ya duerme

Sobre mis ojos en vela.

$$
(P P, \mathrm{XII}, \text { 9-12) }
$$

La lámpara abre su huella

Sobre el diván indolente.

$$
\text { (PP, XXII, 2-3) }
$$

Posteriormente estos términos se convertirán en abstracciones, símbolos. Si la noche va a ir adquiriendo significaciones de carácter destruccionista, los vocablos antes citados irán adquiriendo valores positivos, creacionistas. Se convierten en objetos que salvan de la oscuridad y las sombras, que permiten encontrar el norte al que se encuentra desorientado, que otorgan esperanza al desesperanzado, ánimo al desalentado.

La luna pasa a convertirse en el lugar donde se cumple el último deseo del poeta, donde tiene lugar el olvido supremo, el olvido de un olvido. De esta manera se presenta en el poema V de Donde habite el olvido, en estos versos - tan cercanos, por otra parte, a los de la mística española:

Voy a morir de un deseo,

Si un deseo sutil vale la muerte;

A morir sin mí mismo de un deseo

Sin despertar, sin acordarme,

Allá en la luna, perdido entre su frío

$$
\text { (DON, V, 13-17) }
$$

Las estrellas son metáfora del amante:

Hacia el último cielo

Donde estrellas

Sus labios dan hacia otras estrellas.

$$
\text { (RÍO, “Todo es por amor”, 13-15) }
$$


La lámpara puede ser tanto símbolo de tristeza —condensación del pasado perdido-,

Perder placer es triste

Como la dulce lámpara sobre el lento nocturno

$$
\text { (DON, VII, 5-6) }
$$

cuanto iluminación del mundo oscuro y triste en el que se está desenvolviendo la vida. En este sentido, adquiere la dimensión evangélica ("yo soy la luz del mundo") tras un proceso de personificación. En "No sé qué nombre darle a mis sueños" Cernuda se nos muestra "en tiempo del crepúsculo", en un estado de desesperanza por la incomprensión de los "hombres sordos". En ese momento

La vida puso entonces una lámpara

Sobre muros sangrientos;

El día ya cansado secaba tristemente

Las futuras auroras, remendadas

como harapo de rey.

La Lámpara eras tú, Mis labios, mi sonrisa,

Forma que hallan mis manos en todo lo que alcanzan.

(RÍO, "No sé qué nombre...", 13-20)

En cuanto a luz, posee varios valores, esencialmente positivos, como evidente contraposición a los significados de sombra y noche. La luz puede ser el amor, el amor del otro

No les dejéis marchar porque sonríen

Como la libertad sonríe,

Luz cegadora erguida sobre el mar.

(PLA, "Los marineros son las alas del amor", 9-11)

o el amor del propio Cernuda

Canté, subí

Fui luz un día

Arrastrado en la llama

Como un golpe de viento

Que deshace la sombra

Caí en lo negro

En el mundo insaciable.

(DON, IV, 7-13)

$\mathrm{Y}$, sin embargo, vine como luz.

(RÍO, “Como el viento", 15)

En ocasiones, sin embargo, la luz adquiere valores semánticos relacionados con el dolor, en tanto que evidencia la soledad en la que se encuentra el poeta. Además, puede romper los deliciosos equívocos sensuales que la penumbra favorecía. En el poema "Elegía" el poeta se ilusiona ante lo que su imaginación vislumbra como un contorno desnudo de una estatua que ha cobrado vida. Se complace en esta "equívoca delicia" hasta 
que la claridad del alba le hace ver que todo ha sido fruto de su imaginación, de la penumbra en la que oscila la luz de una tímida lámpara. Del mismo modo, en "Telarañas cuelgan de la razón", la presencia de la luz se vuelve cruel manifestación de la soledad en la que se encuentra el poeta. Ha pasado "el huracán del amor" dejando "un paisaje de ceniza absorta" sobre el que incide la luz del día

El día, esa luz que abraza estrechamente un triste muro

Un muro, ¿no comprendes?,

Un muro frente al cual estoy solo.

$$
\text { (PLA, “Telarañas...”, 19-21) }
$$

Por último, la luz es también el símbolo del conformismo, de la costumbre social, y, por tanto, Cernuda la combate como combate a la sociedad toda.

La seguridad, ese insecto

Que anida en los volantes de la luz.

( $P L A$, "He venido para ver", 27-28)

\section{b) La noche como principio pasivo}

$\mathrm{El}$ primero de los rasgos simbólicos de la noche, según vimos en la definición de $\mathrm{J}$. E. Cirlot, es el de "principio pasivo". La noche es el tiempo del descanso de la actividad humana y, como tal, adquiere el valor de la espera en términos genéricos. Es una etapa de letargo, de aparente inactividad, de compás de espera.

Respecto de las primeras poesías, J. M. Aguirre escribe: "Tres hechos inmediatamente impresionan al lector cuidadoso de los primeros poemas de Luis Cernuda:

1) la atmósfera de indolente emoción que, alguna manera, los unifica,

2) la constante alusión en ellos a la noche,

3) la precisión con que están escritos". 21

Del total de veintitrés poemas que componen el libro, al menos diecisiete de ellos se desarrollan entre la noche, el crepúsculo o el atardecer, es decir, en el "periodo de tiempo opuesto al día". Abundan los sintagmas que hacen referencia a la inactividad: ingrávida somnolencia, tibio vacio, ingrávido presente, inmóvil paroxismo. Es frecuente en los versos la combinación de elementos nocturnos y el quietismo:

El tiempo en las estrellas.

$$
(P P, \mathrm{III}, 17)
$$

Ya la luz se ha dormido

$$
(P P, \mathrm{XVI}, 2)
$$

Bajo esta aparente quietud, no obstante late el impulso inquieto del afán, que convierte a la noche en reflejo de la situación interior del poeta. Hay noche en el exterior porque en el mundo interno todo es una borrosa penumbra. El poeta se siente descon-

21 J. M. Aguirre, "Primeras poesias de Luis Cernuda”, en: Derek Harris, obra citada, pp. 215-227. 
certado y adopta una actitud inactiva en la que la noche sirve de complemento perfecto. Es lo que Aguirre, en el artículo citado, llama "la noche oscura del deseo sexual".

Otro aspecto relacionado con este valor pasivo de la noche lo encontramos cuando ésta se convierte en el momento de la reflexión, de la meditación acerca del tiempo pasado. El poeta, cansado del veloz discurrir del tiempo, se detiene de cuando en cuando para, refugiado en el silencio y la oscuridad nocturnos, recapitular sobre lo pasado. El análisis de la interioridad en Cernuda suele conducir a un agrandamiento de los aspectos negativos, como el desengaño o la frustración:

Desengañada alienta en ti mi vida
Oyendo en el pausado retiro nocturno
Ligeramente resbalar las pisadas
De los días juveniles ...

(INV, "Himno a la tristeza", 5-8)

\section{c) La noche como génesis de tristeza}

Relacionado intrínsecamente con el valor pasivo de la noche, se encuentra el de la tristeza. La ambivalencia de la noche estriba en que representa para el poeta el encuentro con el amor y la constatación de su soledad, elementos ambos que en ocasiones se producen en momentos distintos y que en otras ocasiones $-\mathrm{y}$ entonces surge el dolor más profundo-, suceden a la vez. El encuentro con el amor, el paso del "huracán del amor", deja un poso de insatisfacción que no es posible eliminar. La reacción inmediata entonces es la desesperanza, el nihilismo; la reflexión sobre ese momento conduce a la tristeza.

Así lo vemos en "Razón de las lágrimas", de Un río, un amor. La inmensidad de la tristeza nocturna abre la composición ("La noche por ser triste carece de fronteras") mientras el poeta sueña "con amantes que acuchillan estrellas". Pero enseguida se da cuenta de que es inútil la esperanza, que la noche está fuera y dentro de él mismo y no puede ofrecer otra cosa que lo que es: ausencia de luz, desconcierto, desvario ("la noche no puede ser más que noche"). El poema termina con una imprecación a la noche como una hembra lasciva, imprecación que se mueve entre los dos polos del temor y de la búsqueda de lo prohibido.

La noche, la noche deslumbrante

Que junto a las esquinas retuerce sus caderas,

Aguardando, quién sabe,

Como yo, como todos.

La noche como génesis de la tristeza representa un paso hacia la autodestrucción, trayecto que el poeta recorre como impulsado por una voluntad ineludible.

\section{d) La noche como espacio del horror}

Este valor de la noche está presente desde la antigüedad. La oscuridad va asociada, posiblemente desde los orígenes del ser humano, con seres terribles, fantasmas y monstruos. La ausencia de luz, la oscuridad, produce un terror que a veces no puede ser expresado 
con palabras. La noche es el cobijo de fantasmas, de gritos, de seres nebulosos, de ruidos aterradores, de espantos.

En Cernuda esta dimensión va a irse produciendo también progresivamente a lo largo de su obra. En un primer momento, en Primeras poesias, abunda la prosopopeya para referirse a la noche o a la luz débil. Esta significación de carácter activo, lograda mediante el citado recurso estilístico, suele realizarse generalmente por medio de términos que implican alguna suerte de inquietud o de amenaza

Acreciente la noche

Sus sombras ...

$$
(P P, \mathrm{XVI}, 13-14)
$$

El crepúsculo huye

Anegándose en sombras

Las fugitivas luces

$$
(P P, \mathrm{I}, 14-16)
$$

La sombra misteriosa ya suplanta

Entre el boscaje ávido y sombrío

A la luz tan diáfana que huye

$$
\text { (EGL, "Oda", 116-118) }
$$

Va la sombra invasora

Despojando el espacio

$Y$ la luz fugitiva

Huye a un mundo lejano.

$$
(P P, \mathrm{XXI}, 1-4)
$$

El vocablo horror, asociado a la noche, aparece ya desde Égloga, elegía, oda.

Silencio. Ya decrecen

Las luces que lucían (...)

El cielo ya no canta

Ni su celeste eternidad asiste

A la luz y a las rosas,

Sino al horror nocturno de las cosas.

$$
\text { (EGL, “Égloga", 118-119 y 126-130) }
$$

A partir de los libros surrealistas cernudianos, la asociación horror-noche va a ser frecuente. La noche se carga de seres oscuros, imprecisos, nebulosos, seres en ruina física o moral. Habitualmente también, uno de esos fantasmagóricos personajes es el propio poeta, por lo que la dimensión del horror adquiere una dimensión internalizada.

Cuando la noche adquiere este valor de 'horror', los libros están cargados de términos como niebla, nube, bruma, referidos a esa nebulosa fantasmagoría. También son frecuentes los términos ceniza y ceniciento, y muy abundante el adjetivo gris, en construcciones del tipo hombre gris. En este mismo sentido hay que anotar el valor de sombra. Con todos 
estos términos se pretende crear ese ambiente de vagorosa imprecisión que genere el horror ante lo desconocido y lo no tangible.

\section{e) La noche como muerte}

La relación entre la Muerte y la Noche se establece desde la antigüedad y afecta tanto a los estamentos cultos como a los estratos populares. ${ }^{22} \mathrm{La}$ igualación entre ambos elementos se produce por medio de un proceso metonímico en el que una de las fases principales surge al poner en relación la noche y el sueño ${ }^{23}$.

En Cernuda es importante, como se vio en el análisis cuantitativo del léxico, la presencia de los términos dormir, soñar y sueños. Generalmente los dos últimos tienen una significación positiva, mientras que el primero connota negativamente. Dormir presenta el valor de 'no estar despierto al pulso de la vida', por lo que puede suceder mientras es de día.

No sé por qué, si la luz entra,

Los hombres andan bien dormidos

Recogiendo la vida su apariencia

$$
\text { (RÍO, “Oscuridad completa", 1-3) }
$$

Posteriormente, esta asociación se relacionará directamente con la muerte.

A través de una noche en pleno día

Vagamente he conocido a la muerte.

$$
\text { (RÍO, "Habitación de al lado", 1-2) }
$$

Se inicia así ese camino hacia el aniquilamiento, hacia la destrucción, en el que no falta el dolor, elemento de gran importancia en relación con la noche.

El dolor también busca errante entre la noche.

$$
\text { (RÍO, "Decidme anoche", 13) }
$$

La noche muestra su lado cruel, su ala generadora de dolor. Se trata de un sentimiento anímico, pero que se convierte en algo físico, casi táctil. El dolor presenta un componente de realidad directa. En el plano anímico encontramos, por un lado, el valor de la soledad y, por otro, el del remordimiento. El primero de los poemas de corte surrealista lleva como título precisamente "Remordimiento en traje de noche".

El dolor irá progresivamente acercándose a la muerte. El muerto será el propio poeta, que se transforma en un ser fantasmal, como señalábamos antes. Son abundantes los versos en los que Cernuda se contempla a sí mismo como un muerto viviente, como un cascarón vacío en el que no palpita el pulso de la vida.

\footnotetext{
22 Según la mitología griega, uno de los hijos de la Noche es Tánatos (Cfrt. Félix Guirand, Mitología General, Barcelona, Labor, 1971, p. 238).

23 Hipnos es otro de los hijos de la Noche (idem).
} 
Fantasma que desfila prisionero de nadie

Falto de voz, de manos, apariencia de vida,

Como llanto impotente por las ramas ahogado

(RÍO, "Decidme anoche", 17-19)

Un hombre gris avanza por la calle de niebla,

No lo sospecha nadie. Es un cuerpo vacío;

Vacío como pampa, como mar, como viento,

Desiertos tan amargos bajo un cielo implacable.

(RÍO, "Remordimiento en traje de noche", 1-4)

El poeta sabe que, tras la pérdida del amor, se llega a la autoaniquilación. Si es el amor el impulso vital, la fuerza generadora de toda energía, la ausencia de éste significa muerte, lógicamente. Muerte es, por tanto, sinónimo de desamor:

No es el amor quien muere,

Somos nosotros mismos.

$$
\text { (DON, XII, 1-2) }
$$

La soledad poblé de seres a mi imagen

Como un dios aburrido;

Los amé si eran bellos,

Mi compañía les di cuando me amaron,

$\mathrm{Y}$ ahora como ese mismo dios aislado estoy

Inerme y blanco tal una flor cortada.

(INV, "Himno a la tristeza", 14-19)

Por eso, lo único deseable es el estado último en este proceso de autodestrucción, la fase ulterior del recorrido: el olvido. El poeta ya no trata de buscar la muerte sino de dar un paso más, de llegar a la nada más absoluta, de borrar todo vestigio de que alguna vez se ha existido. Este deseo es el eje motriz de la colección de poemas Donde habite el olvido, poblado de referencias al abandono de la memoria. En el primero de los poemas que componen la serie alude a ese deseo de vivir en el espacio "donde habite el olvido", donde sea tan insignificante como la memoria de una piedra escondida- "sepultada", dice Cernuda - entre las ortigas. La imagen se condensa aún más en el poema XI, donde se expone la filosofia absolutamente desencantada del autor, cuyo deseo final será ahora el de "olvidar un olvido", esto es, lograr el estado de inconsciencia pleno en el que todo vestigio del pasado quede anulado. Para lograrlo es necesaria no sólo la muerte física, sino también la espiritual, el nihilismo en definitiva.

Por último, el doble valor, positivo y negativo, que suelen llevar los términos relacionados con la noche, lo encontramos también en los términos más destructivos, como muerte. Si por un lado representa el final de todo, por otro significa la única salida posible $y$, en consecuencia, se convierte en apetecible. Esta paradoja permite a Cernuda dejar siempre abierta una puerta abierta a la esperanza, al amor. 


\section{Conclusiones}

Como hemos ido viendo, hay una evolución en el tratamiento de la noche por parte de Luis Cernuda, que, por un proceso de internalización de la realidad, pasa de ser espacio exterior a noche interior, prolongación del estado anímico del autor. Si simplificamos, podríamos establecer como palabras claves las que, según el recuento léxico, más se repiten asociadas a la noche y, en base a ellas, delimitar tres momentos,

$$
\text { NOCHE — SOMBRA — MUERTE (Olvido) }
$$

que se corresponderán con la división tripartita del libro, inicial, surrealista y de corte romántico

$\begin{array}{lcc}\text { INICIAL } & \text { SURREALISTA } & \text { ROMÁNTICA } \\ \text { Noche } & \text { Sombra } & \text { Muerte (Olvido) }\end{array}$

Por otra parte, hemos visto cómo los términos referidos a la noche poseen siempre una ambigüedad significativa, relacionada con valoraciones positivas o negativas. Esta ambigüedad no deja de ser sino una manifestación última de la íntima contradicción del poeta, manifestada ya desde el título de su libro, La realidad y el deseo.

Se ha indicado repetidas veces que Cernuda es un poeta del amor. ${ }^{24}$ Porque, en definitiva, sabe que sólo en el otro adquiere sentido la vida, a pesar de todas las contradicciones. El Narciso está abocado a llevar en sí la condena de una desazonadora esterilidad, de un inocuo sinsentido. Sólo cuando se encuentra al otro se puede pensar realmente en la vida, en la luz, en el día. Y eso insisto, a pesar de cualquier paradoja.

Libertad no conozco sino la libertad de estar preso en alguien

Cuyo nombre no puedo oír sin un escalofrío:

Alguien por quien me olvido de esta existencia mezquina,

Por quien el día y la noche son para mí lo que quiera,

Y mi cuerpo y espíritu flotan en su cuerpo y espíritu,

Como leños perdidos que el mar anega o levanta,

Libremente, como la libertad del amor,

La única libertad que me exalta,

La única libertad por que muero.

Tú justificas mi existencia.

Si no te conozco, no he vivido;

Si muero sin conocerte, no muero, porque no he vivido.

( $R I O O$, "Si el hombre pudiera decir", 14-25)

${ }^{24}$ L. Maristany en: "La poesía de Luis Cernuda", recogido en: Derek Harris, obra citada, pp. 185-202, escribe: "Su poesía reclama el amor-sentimiento y apetencia física [...] Son una constante en su obra poética el reconocimiento y la exaltación del amor tal como él los sentía". 


\section{Bibliografía}

Aguirre, J. M., "Primeras poesías de Luis Cernuda" en: Derek Harris, Obra citada., pp. 215-227.

Alvar, M., "La "Noche oscura" de Dámaso Alonso", en: «Cuadernos Hispano Americanos», 280-282/1973, pp. 112-175.

Capote Benot, J.M.

El periodo sevillano de Luis Cernuda. Madrid, Gredos 1971;

El surrealismo en la poesía de Luis Cernuda. Sevilla, Universidad, 1976.

(Ed.), Luis Cernuda, Antología. Madrid, Cátedra, 1981.

Cernuda, Luis

$-L$ a realidad y el deseo. $4^{\mathrm{a}}$ ed., México, F.C.E., 1964;

- Ocnos. Barcelona, Seix-Barral, 1989;

- Poesía y Literatura, I y II. Barcelona, Seix-Barral, 1971;

- Crítica, ensayos y evocaciones, Barcelona, Seix-Barral, 1970 (ed. de Luis Maristany).

Cirlot, J.E., Diccionario de símbolos. $4^{\text {a }}$ ed., Barcelona, Labor, 1981.

Flys, M. J. (ed.), La realidad y el deseo. Madrid, Castalia, 1982.

García De La Concha, V., Historia y critica de la Literatura Española. Época contemporánea: 1914-1939. Barcelona, Crítica, 1984.

Guirand, F., Mitología general. Barcelona, Labor, 1971.

Harris, D., Luis Cernuda. Madrid, Taurus, 1977.

«Insula», Madrid, 207/1964.

Maristany, L., "La poesía de Luis Cernuda" en: Derek Harris, Ob. cit., pp. 185-202.

Molina, R., "La conciencia trágica del tiempo. Clave esencial en la poesía de Luis Cernuda", en: Derek Harris, Ob. cit., pp. 102-110.

Otero, C. "Cernuda, poeta de Europa" en: «Papeles de son Armadans», XXIX/1963, pp. 127-137.

Paz, O., "La palabra edificante" en: «Papeles de son Armadans», XXXV/1964.

Zuleta, E., "La poética de Luis Cernuda" en: Cinco poetas españoles. Madrid, Gredos, 1971. 


\section{NOČ V PRVI IZDAJI ZBIRKE "LA REALIDAD Y EL DESEO" (RESNIČNOST IN ŽELJA) LUISA CERNUDE}

Avtor članka se želi približati simbolnemu svetu Luisa Cernude $\mathrm{z}$ analizo pomenskega polja besede noč v obdobju izoblikovanja Cernudovega pesniškega jaza, v pesnikovi zgodnji poeziji zbrani v zbirki "La realidad y el deseo". Pri analizi simbolne vrednosti noč $i$ avtor ugotavlja, da je termin dvoumen, negativen in pozitiven hkrati, ter pride do zaključka, da se pomensko polje te besede spreminja in ustreza različnim obdobjem v Cernudovem pesniškem ustvarjanju. Pomensko polje besede noč ponazori s ključnimi besedami noč, senca in smrt (pozaba), ki se povezujejo z začetnim, nadrealističnim in romantičnim obdobjem Luisa Cernude. 